\title{
Harmonic Analysis Considering DG Allocation and Load Growth in the Radial Distribution System
}

\author{
Christeen G. Boktor ${ }^{1 *}$, Abdel-Raheem Youssef ${ }^{1}$, Salah Kamel $^{2}$, A. A. Ibrahim² \\ ${ }^{1}$ South Valley University, Dept. of Electrical Engineering, Faculty of Engineering, Qena, \\ Egypt \\ ${ }^{2}$ Aswan University, Dept. of Electrical Engineering, Faculty of Engineering, Aswan, Egypt \\ *corresponding author, E-mail: Eng.CHGB@ @otmail.com
}

Article History: Received: 10 November 2020; Revised 12 January 2021 Accepted: 27 January 2021; Published online: 5 April 2021

\begin{abstract}
In the radial distribution system (RDS), the existence of nonlinear loads causes the generation of harmonic currents, which lead to a lot of problems in the system and equipment, such as electronic equipment is used to control the system due to its effectiveness and accuracy. But these are led to an increase in power losses, equipment will be damaged because of overloads, distortion in voltage and current waveforms. So, the importance of harmonic analysis is increased in the last researches and application for designing and determining its effect in the distribution system. Its benefit appears in finding how much the waveforms for voltage and current are distorted in all the buses in RDS. In this study, we will use the direct approach method to calculate harmonic load flow (HLF) analysis depending on two matrices BIBC and BCBV to determine the relationship between first branch current and bus injection, second branch current with bus voltage. This method is robust and more efficient in solving HLF. It will be applied on IEEE 34 bus system by using a hybrid optimization technique HPOGWO to determine the size for the distributed generated DG. Single, double, and triple units will inject to enhancement voltage profile considering load growth with harmonic sources (HRS) and comparing with the network without HRS.
\end{abstract}

Keywords: radial distribution system; harmonic; distributed generation; optimization; load growth.

\section{Introduction:}

Our needs for Electrical Energy increase rapidly every day, its different application in work, industry, traveling, medical, residence and, so on, increase the electrical energy demand. This rapid increase forced the researchers to develop novel techniques to generate, transmit additional power and control the system by concentrating on the power system performance and make it smarter hour by hour [1].

Because of this, the injection of power electronic and switching devices and nonlinear loads in RDS increases very fast due to their accuracy, fast time response, high efficiency in controlling system. But the harmonic current induced in the system causes a lot of problems, which appear in the high losses, equipment damage interference in the communication system. The voltage and current waveforms are distorted as a result of harmonics. So, the importance of HLF 
solutions is increased in designing and analyzing the RDS to quantify and determine the distortion in waveforms for current and voltage at different busses in the system and find the existence of a resonant problem with its dangerous effect in the system [2].

A lot of methods try to solve HLF, in [3] depend on frequency response and presents a frequency domain. In [4] presents the time domain but one of the disadvantages of this method is the absence of constraints for load flow. In [5] depending on Newton-Raphson for HLF with a repetitive solution.

The Direct Approach is used to solve the HLF solution in RDS, it approves it robust, efficient in large systems [6],[7]. analysis depending on two matrices BIBC and BCBV to determine the relationship between first branch current and bus injection, second branch current with bus voltage. The HRS are inserted in bus 15, 25, 33 for 34_bus system contains 5 order of harmonic 5th, 7th,11th,13th,17th [8].

Load growth is another large problem is faced by the RDS it defined as the normal increase in load per year, it can be solved by expanding the RDS with DG units in the best site and size [9],[10].

In this paper, four cases are discussed in the 34_bus system, direct approach will use to solve HLF and HPOGWO to find the best size of DGs unit inserting in the system, then comparing the results with HRS and without HRS considering single double and triple DG units.

\section{Mathematical Model}

\section{Load flow analysis for RDS}

To discuss and solve the RDS presented in the fundamental load flow [6]

(1) At the kth iteration of load flow the current injection $I_{i}^{k}$ of bus i can be calculated as follow:

$$
I_{i}^{k}=\left(\frac{P_{i}+j Q_{i}}{V_{i}^{k}}\right)^{*}
$$

At bus $i$, the active power is $P_{i}$ and reactive power is $Q_{i}$ the voltage is $V_{i}^{k}$.

(2) Applying KCL to find the branch current and bus injection relationship as follow:

$$
[B]=[B I B C][I]
$$

Where matrix BIBC contains only 0,1 to represent the relationship between branch and injection current.

(3) The relationship between bus voltage and branch current is found by (3):

$$
[\Delta V]=[B C B V][V]
$$

Where matrix BCBV is the impedance matrix represent the branch current to bus voltage relationship.

(4) To find the voltage mismatch by combined (2), (3): 


$$
[\Delta V]=[B C B V][B I B C][I]=[D L F][I]
$$

Where matrix DLF is a combination of $[B I B C]$ and $[B C B V]$

From equation (1)

$$
V^{k+1}=V_{1}-[D L F]\left[I^{k}\right]
$$

At bus i the load impedance $Z_{i}$ can be calculated by:

$$
Z_{i}=\frac{V_{i}}{\left(\frac{P_{i}+j Q_{i}}{V_{i}}\right)^{*}}
$$

\section{HLF analysis}

Harmonic analysis is performed in this section by discus the relationship between harmonic currents, branch currents, and voltages of each harmonic order after finding the effect of harmonic current absorbed by shunt capacitors [2]. The nonlinear loads can be considered as HRS [8].

(1) The vector form in (7) represents the harmonic current by shunt capacitors and nonlinear load:

$$
\left[I^{(h), k}\right]=\left[\begin{array}{c}
I h^{(h), k} \\
\ldots \ldots \\
I S
\end{array}\right]
$$

Where the vector form $\left[I^{(h)}\right]$ is the harmonic current at hth harmonic order. Harmonic currents are developed from both linear and nonlinear load can be presented by $\left[I h^{(h)}\right] .\left[I s^{h}\right]$ is the harmonic current that the shunt capacitor absorbed.

(2) The coefficient vector $[A]$ for branch between two buses $\mathrm{i}$ and $\mathrm{j}$ of harmonic current:

$$
\left[A_{i j}^{(h)}\right]=\left[\begin{array}{c}
A h_{i j}^{(h)} \\
\cdots \cdots \\
A s_{i j}^{(h)}
\end{array}\right]
$$

Where $\left[A h_{i j}^{(h)}\right]$ and $\left[A s_{i j}^{(h)}\right]$ are harmonic current coefficient vectors developed from both linear and nonlinear load in the system and absorbed capacitors, respectively for any branch.

(3) $[H A]$ is the matrix show the relationship between the vector of the system harmonic current and the bus voltage. First to calculate it must find voltage drop in branches by (9):

$$
\Delta V_{i j}^{(h), k}=Z_{i j}^{(h)}\left[A_{i j}^{(h), k}\right]^{T}\left[I^{(h), k}\right]
$$

where $Z_{i j}^{(h)}$ is the branch impedance in hth order of harmonic then [HA] can be calculated by (10):

$$
\left[V^{(h), k}\right]=\left[H A s^{(h), k}\right]\left[I^{(h), k}\right]
$$

(4) To determine [HAss] and [HAsh].the bus voltage for capacitors can e found by (11)

$$
\left[V s^{(h), k}\right]=\left[H A s^{(h), k}\right]\left[I^{(h), k}\right]
$$


Where $\left[H A s^{(h), k}\right]$ is a vector form for the shunt capacitors buses. But equation (11) should be rewritten as follow (12) due to the shunt capacitor i voltage can be calculated by $V s i^{(h), k}=$ $-I s i^{(h), k} * Z s i^{(h)}$,

$$
-\left[\begin{array}{c}
Z s_{1}^{(h)} I s_{1}^{(h), k} \\
\vdots \\
Z s_{n-1}^{(h)} I s_{n-1}^{(h), k} \\
Z s_{n}^{(h)} I s_{n}^{(h), k}
\end{array}\right]=\left[H A s h^{(h), k} \quad \vdots \quad H A s s^{(h), k}\right]\left[\begin{array}{c}
I h^{(h), k} \\
\ldots \\
I s^{(h), k}
\end{array}\right]
$$

(5) For Zs harmonic load impedance for capacitors

$$
\left[Z s^{(h)}\right]=\left[\begin{array}{l}
Z s_{1}^{(h)} \\
Z s_{2}^{(h)}
\end{array}\right]
$$

Then $[H L F]$ can be calculated depending on $\mathrm{Zs}$

$$
[H L F]=[H A s s]+[Z s]
$$

(6) To calculate $\left[I_{s}^{(h)}\right]$ from (12), (14)

$$
\left[H L F^{(h), k}\right]\left[I S^{(h)}\right]=-\left[H A s h^{(h), k}\right]\left[I h^{(h), k}\right]
$$

Depending on (15) y using $\left[I h^{(h), k}\right]$ data to find $\left[I s^{(h)}\right]$

(7) Due to harmonic effect in the system Obtain branch current $\left[B_{i j}{ }^{(h), k}\right]$ and bus voltage $\left[V^{(h), k}\right]$

\section{Load growth calculation}

The increase in load year by year and to determine the growth in any year can be calculated as following [9]:

$$
\begin{aligned}
& P_{L i}(y)=P_{L i}(0) \times(1+g)^{y} \\
& Q_{L i}(y)=Q_{L i}(0) \times(1+g)^{y}
\end{aligned}
$$

Where $\mathrm{g}=7.5 \%$ from base year [9] is the rate of annual growth, $\mathrm{y}$ is the year number, $P_{L}(y)$ and $Q_{L}(y)$ are the active and reactive power at any year, respectively. $P_{L}(0)$ and $Q_{L}(y)$ are the active and reactive load in the base year $(\mathrm{y}=0)$.

\section{Hybrid HPSOGWO algorithm}

To benefit from the ability of two techniques and increase the quality and stability of the solution, so a hybrid optimization technique is used to find the solution. Here depends on grey wolf optimizer GWO and particle swarm optimization PSO to improve exploration and exploitation ability for both techniques.

The hybridization is made at a low or high level [11]. In HPSOGWO the variant runs in parallel and combines variants of two functions. So, it uses a low level [12].

After the modification for the technique, the position of the three agents are updated in the search space and the modification is written as follow [12]:

$$
\begin{aligned}
& \overrightarrow{D_{\alpha}}=\left|\overrightarrow{c_{1}} \cdot \overrightarrow{x_{\alpha}}-\omega * \vec{x}\right| \\
& \overrightarrow{D_{\beta}}=\left|\overrightarrow{c_{2}} \cdot \overrightarrow{x_{\beta}}-\omega * \vec{x}\right| \\
& \overrightarrow{D_{\delta}}=\left|\overrightarrow{c_{3}} \cdot \overrightarrow{x_{\delta}}-\omega * \vec{x}\right|
\end{aligned}
$$

The velocity is updated as following [12]: 


$$
\begin{gathered}
v_{i}^{k+1}=\omega *\left(v_{i}^{k}+c_{1} r_{1}\left(x_{1}-x_{i}^{k}\right)+c_{2} r_{2}\left(x_{2}-x_{i}^{k}\right)+c_{3} r_{3}\left(x_{3}-x_{i}^{k}\right)\right) \\
x_{i}^{k+1}=x_{i}^{k}+v_{i}^{k+1}
\end{gathered}
$$

\section{Constraints}

- Bus voltage constraints

The voltage in the RDS must follow the minimum $\left(V_{\min }\right)$ and maximum $\left(V_{\text {max }}\right)$ limits to keep the system stable.

$$
V_{\min } \leq V_{i} \leq V_{\max }
$$

- $\quad$ DG size limit

$$
\begin{aligned}
& \sum_{i=1}^{N D G} P_{D G}(i) \leq\left(\sum_{i=1}^{k} P_{L}(i)+\sum_{j=1}^{n b} P_{\text {loss }}(j)\right) \\
& \sum_{i=1}^{N D G} Q_{D G}(i) \leq\left(\sum_{i=1}^{k} Q_{L}(i)+\sum_{j=1}^{n b} Q_{\text {loss }}(j)\right)
\end{aligned}
$$

The DG units' size will be less than the power load in the base year $y=0$. In this paper, the lower value that can be injected is $10000 \mathrm{~W}$ and the upper value is $4600000 \mathrm{w}$ less than the power in the bae year for the test system.

- Objective function

The objective function focuses on the voltage profile enhancement and keeps the limit of voltages within 0.9 p.u up to 1.05 p.u.

\section{Simulation results}

In this section, four cases are discussed and applied in the 34_bus system, the direct approach will use to solve HLF and HPOGWO to find the best size of DGs units inserting in the system, then comparing the results with HRS and without HRS considering single double and triple DG units to verify the ability of the method in solving the test system taking in account the load growth calculations, and the four cases are organized as follow:

(1) Without DG without HRS

(2) Without DG with HRS

(3) With DG without HRS

(4) With DG with HRS

- Standard test system

The study will be performed in 34 _bus system RDS [13]. Figure 1 presents the single-line diagram for the test system. The total active and reactive load power at base year $4636.5 \mathrm{~kW}$ 
and $2873.5 \mathrm{kVAR}$, the $V_{\min }$ is at bus 27 equal 0.9417 p.u. HRS are inserted in bus $15,25,33$ for 34_bus system contains 5 orders of harmonic 5th, 7th, 11th,13th,17th [8] and Figure 2 presents the voltage profile at 5 orders of harmonic.

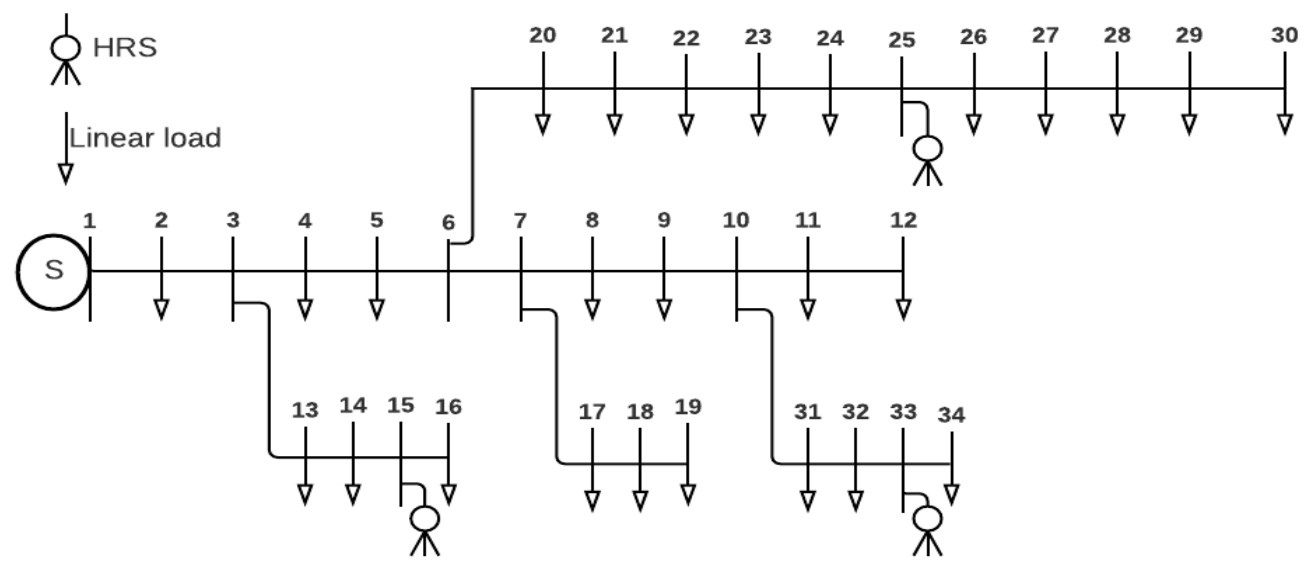

Figure 1. Single line diagram for 34_bus RDS

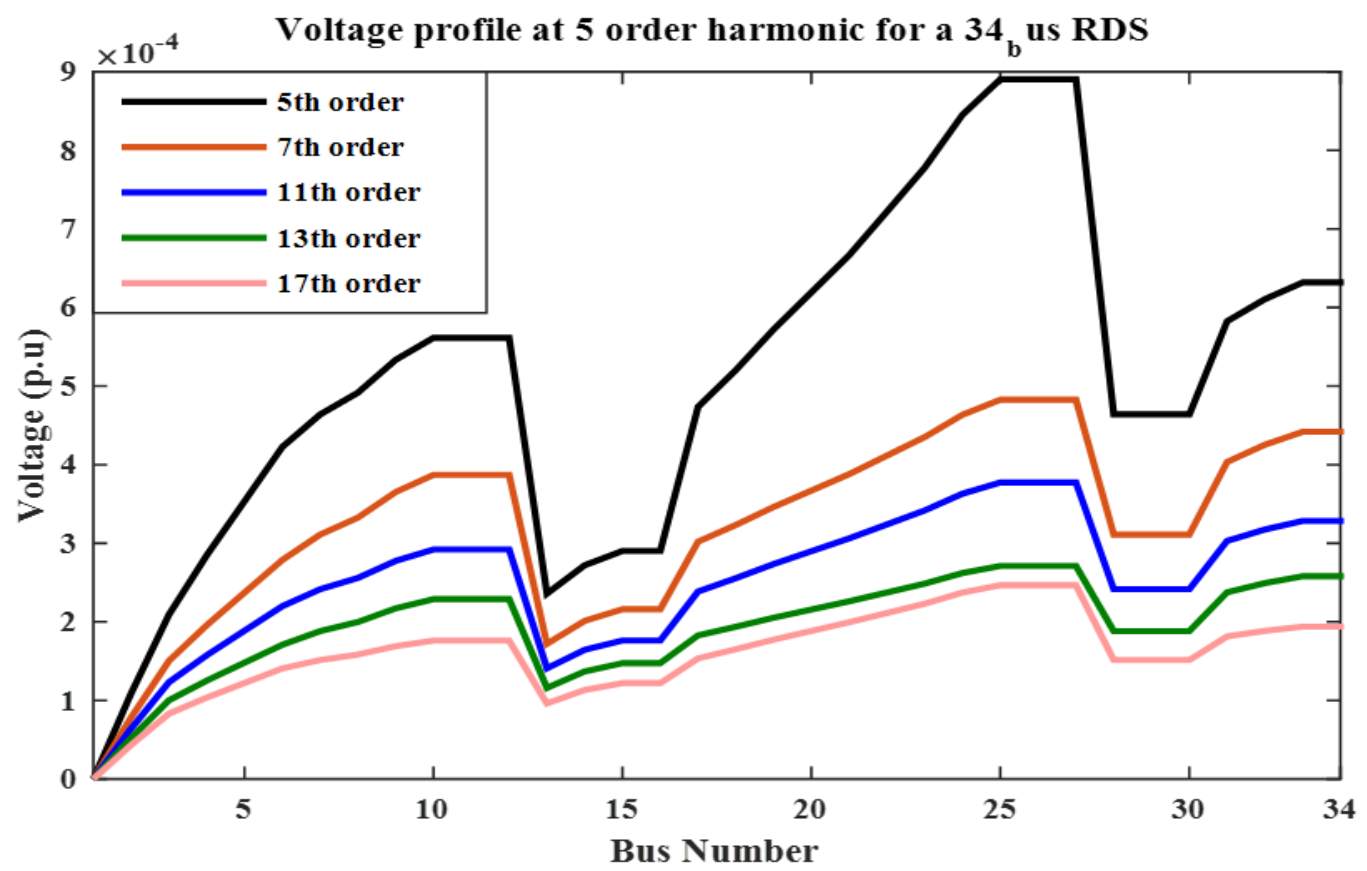

Figure.2. Voltage profile at 5 orders of harmonic

\section{Without DG Without HRS}

In table 1 left side shows the $\left(V_{\text {min }}\right)$ in the system, the violation due to load growth occurs in the 7 th year. Figure 3 shows the voltage profile in the system.

\section{Without DG With HRS}

In table 1 right side shows the $\left(V_{\min }\right)$ in the system the violation due to load growth occurs in the 7th year also the effect of harmonic is appeared here and increases the voltage magnitude 
as shown, (V_bus) is the voltage in the buses before injection the calculations of HLF. Figure 4 shows the voltage profile in the system.

Table1 Result without DG without HRS and with HRS

\begin{tabular}{|l|l|l|l|l|}
\hline \multicolumn{2}{|c|}{ Result without DG without HRS } & \multicolumn{3}{c|}{ Result without DG with HRS } \\
\hline Year & V_min & year & V_bus & V_min after HRS \\
\hline Y0 & 0.9417 & Y0 & 0.9417 & 0.9419 \\
\hline Y1 & 0.9371 & Y1 & 0.9371 & 0.9373 \\
\hline Y2 & 0.932 & Y2 & 0.932 & 0.9323 \\
\hline Y3 & 0.9266 & Y3 & 0.9266 & 0.9269 \\
\hline Y4 & 0.9206 & Y4 & 0.9206 & 0.9210 \\
\hline Y5 & 0.9142 & Y5 & 0.9142 & 0.9146 \\
\hline Y6 & 0.9072 & Y6 & 0.9072 & 0.9076 \\
\hline Y7 & 0.8995 & Y7 & 0.8995 & 0.8999 \\
\hline
\end{tabular}

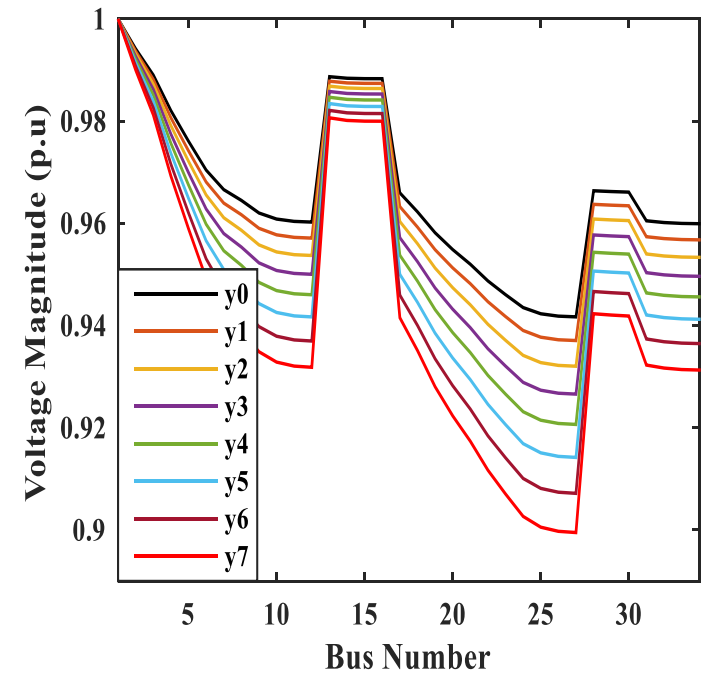

Figure.3. Voltage profile for 34 bus RDS without DG without HRS

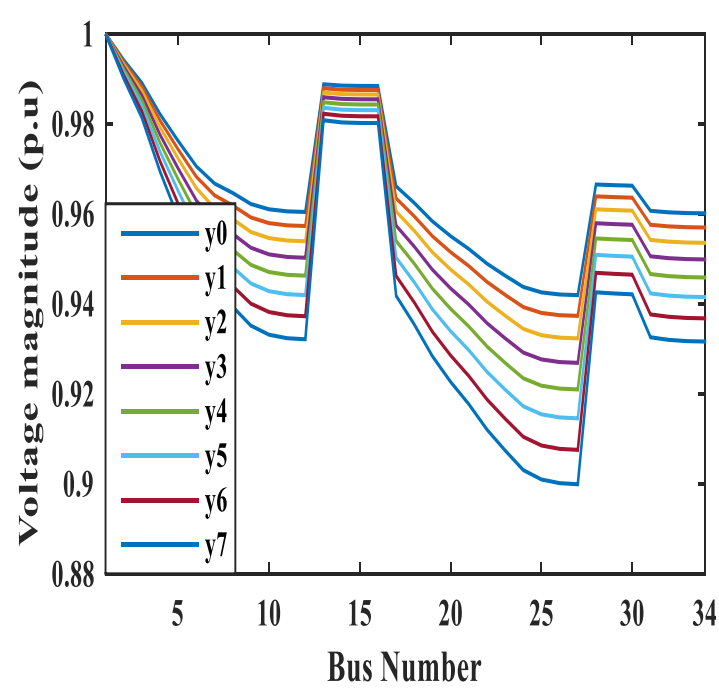

Figure.4. Voltage profile for 34 bus RDS without DG with HRS

\section{With DG Without HRS}

a) Inserting single DG

In table 2 presents the DG size inserted in the system for each year. the RDS will stand for 15 years and withstands annually increased loads by load growth. Figure 5 presents the voltage profile for this case. Where pgt is the total power injected by the DG unit.

\section{b) Inserting double DGs}

In table 2 two DG units will be inserted in the system, the RDS will withstand for 13 years without violation and the voltage and system limits are within the constraints. Figure 6 presents the voltage profile. 


\section{c) Inserting triple DGs}

In table 2 also three DG units will be inserted in the system the RDS will withstand for 13 years, Figure 7 presents the voltage profile. the total DG size for 3 units in the year 13th equals $4169577 \mathrm{w}$ and that is less than the load power in the base year and be within constraints.

Table2 Result with DG without HRS:

\begin{tabular}{|l|l|l|l|l|l|l|l|}
\hline & \multicolumn{2}{|c|}{$\begin{array}{c}\text { Result with 1 DG } \\
\text { without HRS }\end{array}$} & \multicolumn{2}{c|}{$\begin{array}{c}\text { Result with 2 DG without } \\
\text { HRS }\end{array}$} & \multicolumn{2}{c|}{ Result with 3 DG without } & \\
\hline year & V_min & Pgt (w) & V_min & Pgt (w) & V_min & Pgt (w) & Load growth (w) \\
\hline Y0 & 0.9419 & 10000 & 0.9420 & 20000 & 0.9421 & 30000 & 4636500 \\
\hline Y1 & 0.9373 & 10000 & 0.9373 & 20000 & 0.9375 & 30000 & $4.9842^{*} 10^{\wedge} 6$ \\
\hline Y2 & 0.9323 & 10000 & 0.9323 & 20000 & 0.9325 & 30000 & $5.3581^{*} 10^{\wedge} 6$ \\
\hline Y3 & 0.9268 & 10000 & 0.9268 & 20000 & 0.9270 & 30000 & $5.7599^{*} 10^{\wedge} 6$ \\
\hline Y4 & 0.9209 & 10000 & 0.9209 & 20000 & 0.9211 & 30000 & $6.1919^{*} 10^{\wedge} 6$ \\
\hline Y5 & 0.9145 & 10000 & 0.9145 & 20000 & 0.9146 & 30000 & $6.6563^{*} 10^{\wedge} 6$ \\
\hline Y6 & 0.9074 & 10000 & 0.9074 & 20000 & 0.9076 & 30000 & $7.1555^{*} 10^{\wedge} 6$ \\
\hline Y7 & 0.9 & 18713 & 0.9 & 30919 & 0.9 & 33536 & $7.6922^{*} 10^{\wedge} 6$ \\
\hline Y8 & 0.9001 & 324943 & 0.9 & 425646 & 0.9001 & 381679 & $8.2691^{*} 10^{\wedge} 6$ \\
\hline Y9 & 0.9 & 648415 & 0.9 & 850238 & 0.9002 & 778363 & $8.8893^{*} 10^{\wedge} 6$ \\
\hline Y10 & 0.9001 & 1006175 & 0.9001 & 1312879 & 0.9001 & 1151306 & $9.556^{*} 10^{\wedge} 6$ \\
\hline Y11 & 0.9 & 1394717 & 0.9 & 1806337 & 0.9 & 1621132 & $1.02^{*} 10^{\wedge} 7$ \\
\hline Y12 & 0.9 & 1843984 & 0.9 & 2408930 & 0.9002 & 2406943 & $1.104^{*} 10^{\wedge} 7$ \\
\hline Y13 & 0.9 & 2337691 & 0.9022 & 4490697 & 0.9027 & 4169577 & $1.187^{*} 10^{\wedge} 7$ \\
\hline Y14 & 0.9 & 2921613 & 0.8204 & 20000 & 0.8206 & 30000 & $1.276^{*} 10^{\wedge} 7$ \\
\hline Y15 & 0.9 & 4144471 & - & - & - & - & $1.372^{*} 10^{\wedge} 7$ \\
\hline Y16 & 0.7847 & 10000 & - & - & - & - & $1.475^{*} 10^{\wedge} 7$ \\
\hline
\end{tabular}

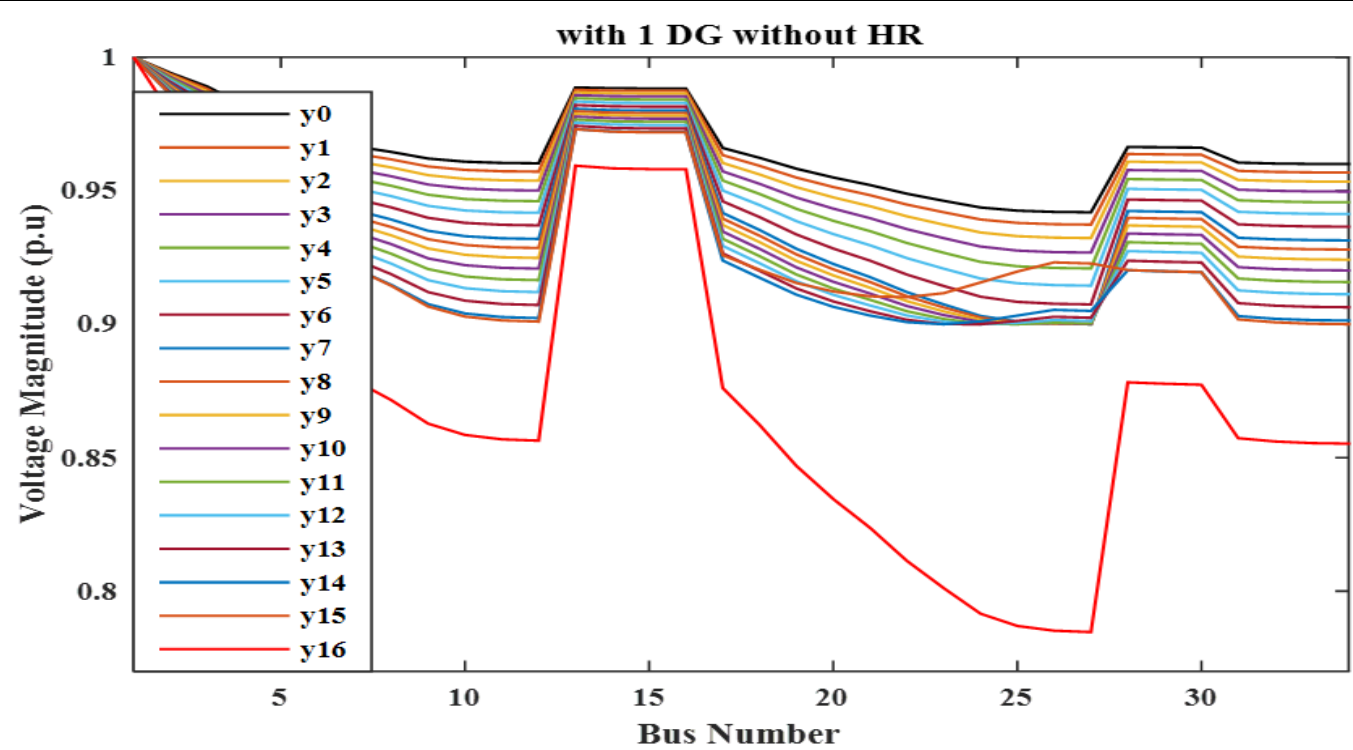

Figure.5. Voltage profile for 34 bus RDS with 1 DG without HRS 


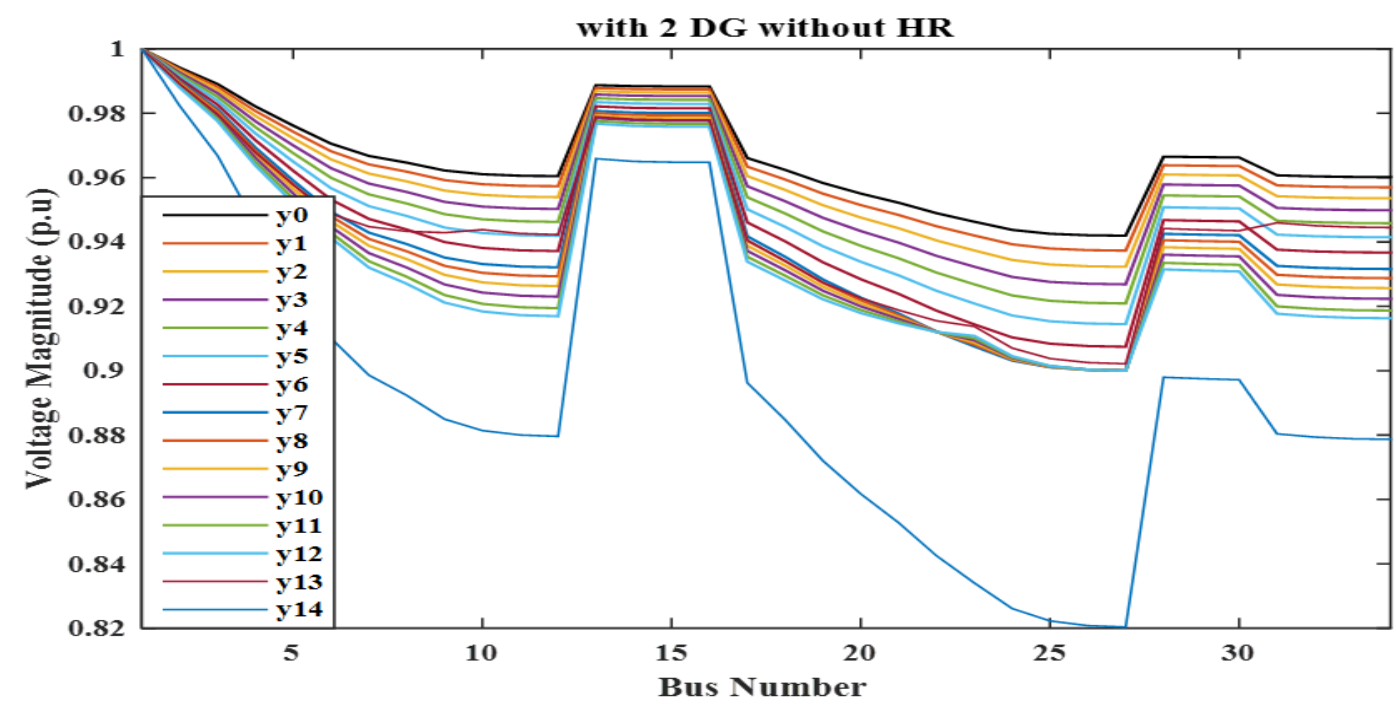

Figure.6. Voltage profile for 34 bus RDS with 2 DG without HRS

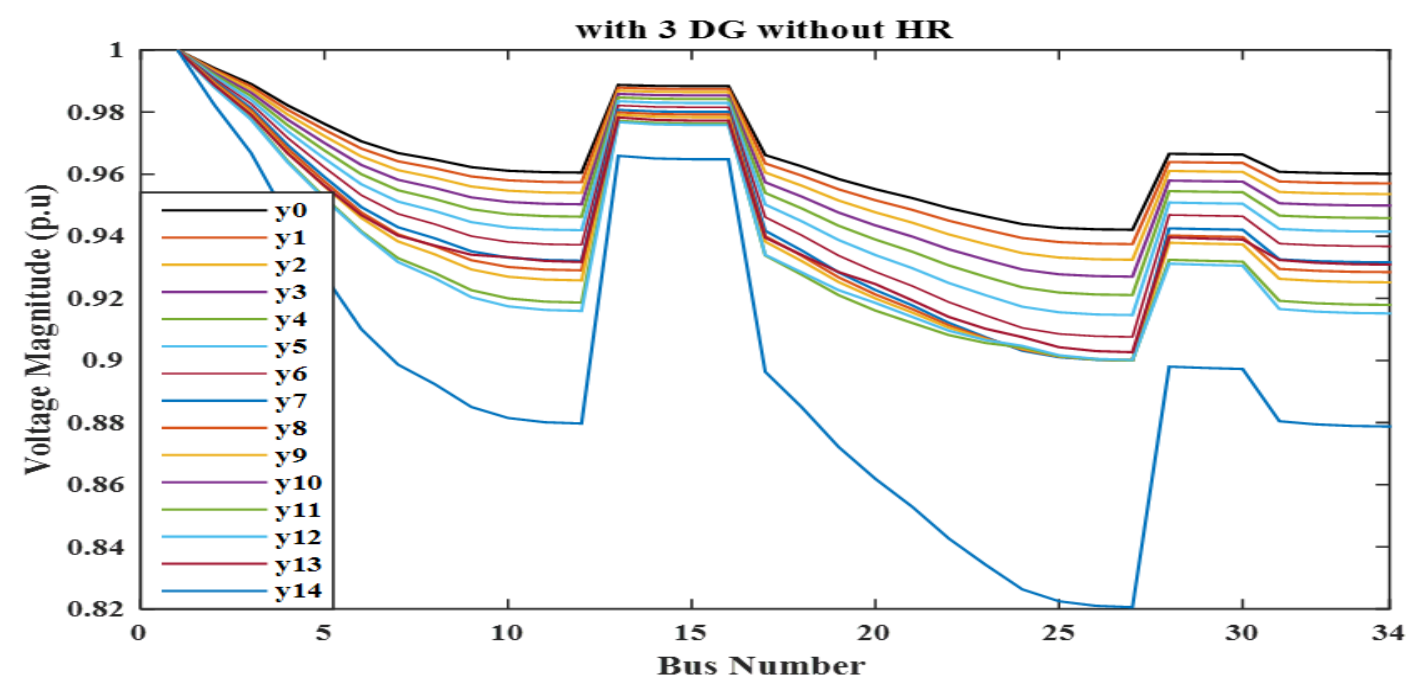

Figure.7. Voltage profile for 34 bus RDS with 3 DG without HRS

\section{With DG With HRS}

a) Inserting single DG

Table 3 will list the result for the system with 1 DG unit, the difference between the voltage magnitude results in case 3 (a) and here in case 4 (a) and the increase in voltages as an effect of HRS existence, this will reflect on the DG's size which decreases here and appear from year 7. Figure 8 shows the voltage profile.

\section{b) Inserting double DGs}

In table 3 the system will still stable for 13 years the load injected in this year is less than the load in the base year also the summation of Pgt for the system injected for all years with HRS is less than in the same case without HRS. Figure 9 represents the voltage profile.

\section{c) Inserting triple DGs}

Finally, table 3 also presents the result under load growth calculations. The system will still stable for 13 years. Increases the number of DG units in the RDS enhancement the voltage 
profile and decreases the total size that will be inserted in the system as is shown in the next table. Figure 10 represents the voltage profile.

Table3 Result with DG with HRS:

\begin{tabular}{|l|l|l|l|l|l|l|l|l|l|l|l|}
\hline & \multicolumn{2}{|c|}{ Result with 1 DG with HRS } & \multicolumn{2}{|c|}{ Result with 2 DG with HRS } & \multicolumn{2}{l|}{ Result with 3 DG with HRS } & \\
\hline year & V_bus & V_min & Pgt $(w)$ & V_bus & V_min & Pgt (w) & V_bus & V_min & Pgt (w) & Load growth (w) \\
\hline Y0 & 0.9419 & 0.9422 & 10000 & 0.9420 & 0.9422 & 20000 & 0.9421 & 0.9424 & 30000 & 4636500 \\
\hline Y1 & 0.9373 & 0.9376 & 10000 & 0.9373 & 0.9376 & 20000 & 0.9375 & 0.9377 & 30000 & $4.9842^{*} 10^{\wedge} 6$ \\
\hline Y2 & 0.9323 & 0.9326 & 10000 & 0.9323 & 0.9326 & 20000 & 0.9325 & 0.9327 & 30000 & $5.3581^{*} 10^{\wedge} 6$ \\
\hline Y3 & 0.9268 & 0.9271 & 10000 & 0.9268 & 0.9272 & 20000 & 0.9270 & 0.9273 & 30000 & $5.7599^{*} 10^{\wedge} 6$ \\
\hline Y4 & 0.9209 & 0.9212 & 10000 & 0.9209 & 0.9212 & 20000 & 0.9211 & 0.9214 & 30000 & $6.1919^{*} 10^{\wedge} 6$ \\
\hline Y5 & 0.9145 & 0.9148 & 10000 & 0.9145 & 0.9148 & 20000 & 0.9146 & 0.915 & 30000 & $6.6563^{*} 10^{\wedge} 6$ \\
\hline Y6 & 0.9074 & 0.9078 & 10000 & 0.9074 & 0.9078 & 20000 & 0.9076 & 0.9080 & 30000 & $7.1555^{*} 10^{\wedge} 6$ \\
\hline Y7 & 0.8998 & 0.9002 & 10000 & 0.8998 & 0.9002 & 20000 & 0.8999 & 0.9004 & 30000 & $7.6922^{*} 10^{\wedge} 6$ \\
\hline Y8 & 0.8996 & 0.9 & 305162 & 0.8995 & 0.9 & 403245 & 0.8996 & 0.9 & 358247 & $8.2691^{*} 10^{\wedge} 6$ \\
\hline Y9 & 0.8995 & 0.9 & 630718 & 0.8995 & 0.9 & 826982 & 0.8995 & 0.9 & 727471 & $8.8893^{*} 10^{\wedge} 6$ \\
\hline Y10 & 0.8995 & 0.9001 & 984840 & 0.8995 & 0.9 & 1284408 & 0.9 & 0.9005 & 1147820 & $9.556^{*} 10^{\wedge} 6$ \\
\hline Y11 & 0.8994 & 0.9 & 1372644 & 0.8995 & 0.9 & 1781293 & 0.8995 & 0.9 & 1558982 & $1.02^{*} 10^{\wedge} 7$ \\
\hline Y12 & 0.8994 & 0.9 & 1819204 & 0.8994 & 0.9 & 2373657 & 0.8994 & 0.9 & 2351178 & $1.104^{*} 10^{\wedge} 7$ \\
\hline Y13 & 0.8994 & 0.9 & 2310604 & 0.9006 & 0.9012 & 4331486 & 0.9002 & 0.9008 & 3610725 & $1.187^{*} 10^{\wedge} 7$ \\
\hline Y14 & 0.8994 & 0.9001 & 2894052 & 0.8204 & 0.8211 & 20000 & 0.8206 & 0.8213 & 30000 & $1.276^{*} 10^{\wedge} 7$ \\
\hline Y15 & 0.8994 & 0.9 & 4062338 & - & - & - & - & - & - & $1.372^{*} 10^{\wedge} 7$ \\
\hline Y16 & 0.7847 & 0.7856 & 10000 & - & - & - & - & - & - & $1.475^{*} 10^{\wedge} 7$ \\
\hline
\end{tabular}

with 1 DG with HR

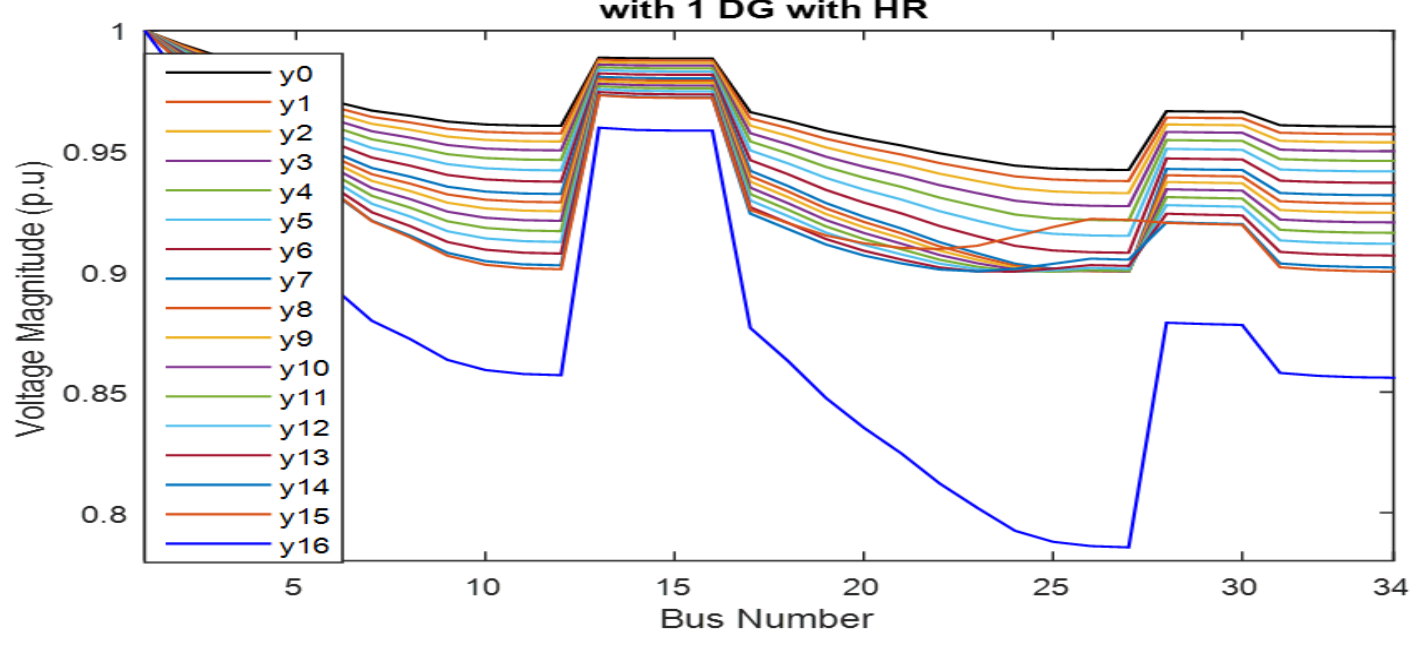

Figure.8. Voltage profile for 34 bus RDS with 1 DG with HRS

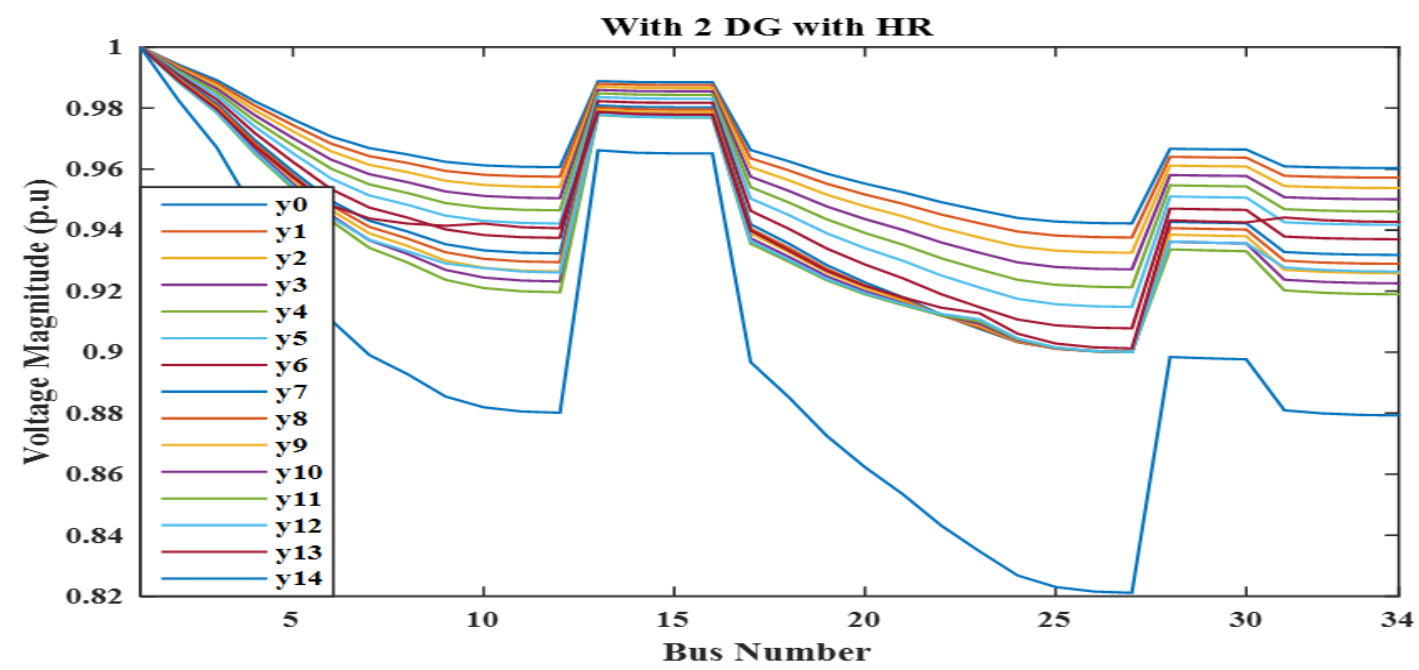

Figure.9. Voltage profile for 34 bus RDS with 2 DG with HRS 


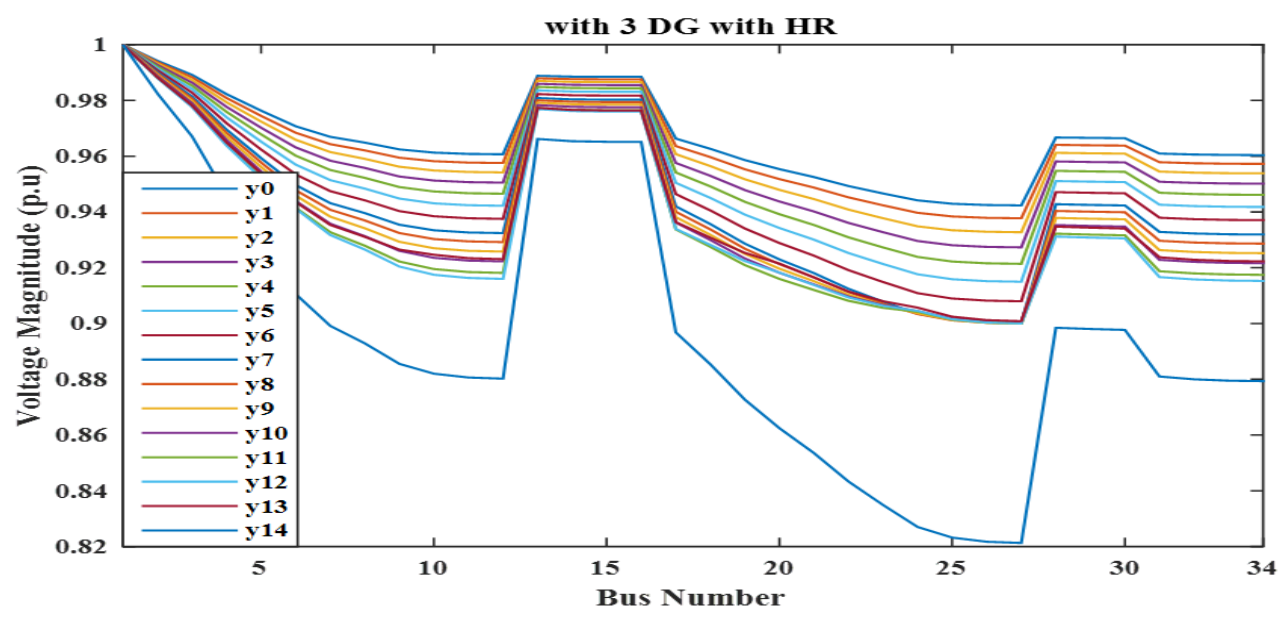

Figure.10. Voltage profile for 34 bus RDS with 3 DG with HRS

\section{Work comparison}

This section will introduce a comparison between results in the case of the existing and absence of HRS. The inserting of nonlinear loads and HRS increase the voltage magnitude of RDS and load flow harmonic distortion and this will affect the DG size that inserted the system and decreases the size of total DG units. Table 4 presents the total power injected into the system pgt from the previous results. From base year to year 7, the system is stable before inserting any DG or HRS as discussed before in case 1 and case 2 and presented in table 1, so the DG units in these years took the lower value of DG as shown in constraints to enhancement the voltage profile only. From year 7 the DG units inserted are used to make the system stable and keep the voltages within constraints and enhancement the voltage profile to sustain the load growth in the system.

Finally, Comparing the result in table 4 presents the decrease in Pgt in presence of HRS than without HRS for example in year 13 for inserting $3 \mathrm{DG}$ units the load injected equal 4.2 MW in case of the absence of HRS but with HRS in the same year equals 3.6 MW with decreased amount reach to $558 \mathrm{~kW}$.

For single, double, and triple DG units the decrease in power due to the presence of HRS as a summation for 16 years reach $251.16 \mathrm{~kW}, 304.575 \mathrm{~kW}$, and $758.113 \mathrm{~kW}$ respectively. It is clear that in case of increasing the DG units also affects decreasing the size in the presence of HRS.

Table4 Result comparison

\begin{tabular}{|l|l|l|l|l|l|l|l|l|l|l|}
\hline year & \multicolumn{3}{|c|}{ Inserting 1 DG } & \multicolumn{3}{c|}{ Inserting 2 DG } & \multicolumn{3}{c|}{ Inserting 3 DG } \\
\hline & $\begin{array}{l}\text { Without } \\
\text { HRS }\end{array}$ & $\begin{array}{l}\text { With } \\
\text { HRS }\end{array}$ & $\begin{array}{l}\text { The } \\
\text { decrease } \\
\text { in Pgt } \\
\mathrm{kW}\end{array}$ & $\begin{array}{l}\text { Without } \\
\text { HRS }\end{array}$ & With HRS & $\begin{array}{l}\text { The } \\
\text { decrease } \\
\text { in Pgt } \\
\mathrm{kW}\end{array}$ & $\begin{array}{l}\text { Without } \\
\text { HRS }\end{array}$ & $\begin{array}{l}\text { With } \\
\text { HRS }\end{array}$ & $\begin{array}{l}\text { The } \\
\text { decrease } \\
\text { in Pgt } \\
\mathrm{kW}\end{array}$ \\
\hline Y0 & 10000 & 10000 & 0 & 20000 & 20000 & 0 & 30000 & 30000 & 0 \\
\hline Y1 & 10000 & 10000 & 0 & 20000 & 20000 & 0 & 30000 & 30000 & 0 \\
\hline Y2 & 10000 & 10000 & 0 & 20000 & 20000 & 0 & 30000 & 30000 & 0 \\
\hline Y3 & 10000 & 10000 & 0 & 20000 & 20000 & 0 & 30000 & 30000 & 0 \\
\hline Y4 & 10000 & 10000 & 0 & 20000 & 20000 & 0 & 30000 & 30000 & 0 \\
\hline Y5 & 10000 & 10000 & 0 & 20000 & 20000 & 0 & 30000 & 30000 & 0 \\
\hline Y6 & 10000 & 10000 & 0 & 20000 & 20000 & 0 & 30000 & 30000 & 0 \\
\hline Y7 & 18713 & 10000 & 8.713 & 30919 & 20000 & 10.919 & 33536 & 30000 & 3.536 \\
\hline
\end{tabular}




\begin{tabular}{|c|c|c|c|c|c|c|c|c|c|}
\hline $\mathrm{Y} 8$ & 324943 & 305162 & 19.781 & 425646 & 403245 & 22.401 & 381679 & 358247 & 23.432 \\
\hline Y9 & 648415 & 630718 & 17.697 & 850238 & 826982 & 23.256 & 778363 & 727471 & 50.892 \\
\hline Y10 & 1006175 & 984840 & 21.335 & 1312879 & 1284408 & 28.471 & 1151306 & 1147820 & 3.486 \\
\hline Y11 & 1394717 & 1372644 & 22.073 & 1806337 & 1781293 & 25.044 & 1621132 & 1558982 & 62.15 \\
\hline $\mathrm{Y} 12$ & 1843984 & 1819204 & 24.78 & 2408930 & 2373657 & 35.273 & 2406943 & 2351178 & 55.765 \\
\hline Y13 & 2337691 & 2310604 & 27.087 & 4490697 & 4331486 & 159.211 & 4169577 & 3610725 & 558.852 \\
\hline Y14 & 2921613 & 2894052 & 27.561 & 20000 & 20000 & 0 & 30000 & 30000 & 0 \\
\hline Y15 & 4144471 & 4062338 & 82.133 & - & - & - & - & - & - \\
\hline Y16 & 10000 & 10000 & 0 & - & - & - & - & - & - \\
\hline $\begin{array}{l}\text { The } \\
\text { total } \\
\text { DG } \\
\text { size }\end{array}$ & 14720722 & 14469562 & 251.16 & 11485646 & 11181071 & 304.575 & 10782536 & 10024423 & 758.113 \\
\hline
\end{tabular}

\section{Conclusion}

The annual load growth and the increase in usage of nonlinear loads in RDS. In this paper, four cases are applied on 34 bus-system to show the effect of HRS and injected DG units in the system. So, it needs to use the direct approach to solve HLF and benefit from the ability of HPSOGWO to find the optimal size of DGs. Single, double, and triple units have been inserted in the RDS. the increase in voltage due to HRS reduced the total DG size that is needed to enhancement the voltage profile and keeps the system stable during the annual increase in load. So, in presence of HRS the DG size decrease and improve the voltage profile.

\section{REFERENCES}

[1] TAGORE, ASHUTOSH KUMAR. "HARMONIC LOAD FLOW ANALYSIS OF RADIAL DISTRIBUTION SYSTEM WITH DG AND D-STATCOM." (2018).

[2] Teng, Jen-Hao, and Chuo-Yean Chang. "Backward/forward sweep-based harmonic analysis method for distribution systems." IEEE Transactions on Power Delivery 22.3 (2007): 1665-1672.

[3] "Modeling and Simulation of the Propagation of Harmonics in Electric Power Network Part 11: Sample Systems and Examples," Task Force on Harmonics Modeling and Simulation, IEEE Trans on Power Delivery, Vol. 11, No. 1, pp. 466-474, Jan. 1996.

[4] R. H. Kitchin, “Converter Harmonics in Power System Using State-Variable Analysis,” IEE Proc. G. T. Heydt and A. W. Galli, "Transient Power.

[5] A. Arunagiri and B. Venkatesh, "Harmonic Load Flow for Radial Distribution Systems," Journal of Engineering Science and Technology, vol. 6, pp. 300-310, 2011.

[6] T. Jen-Hao, “A Direct Approach for Distribution System Load Flow Solution,” IEEE Transactions on Power Delivery vol.18, no. 3, pp. 882-887, July 2003.

[7] T. Jen-Hao and C. Chuo-Yean, "Backward/Forward Sweep

Based Harmonic Analysis Method for Distribution Systems," IEEE Transactions on Power Delivery vol. 22, pp. 1665-1672, 2007.

[8] Shokri, Siti Mariam Mohd, et al. "A direct approach used for solving the distribution system and harmonic load flow solutions." 2013 IEEE 7th International Power Engineering and Optimization Conference (PEOCO). IEEE, 2013.

[9] Das, D., "Maximum loading and cost of energy loss of radial distribution feeders," Int. J. Electr. Power Energy Syst., Vol. 26, No. 4, pp. 307-314, 2004

[10] Boktor, Christeen G., Abdel-Raheem Youssef, and Salah Kamel. "Optimal installation of renewable DG units in distribution system using hybrid optimization technique." 2019 IEEE Conference on Power Electronics and Renewable Energy (CPERE). IEEE, 2019.

[11] E.-G. Talbi, “A taxonomy of hybrid metaheuristics," Journal of heuristics, vol. 8, no. 5, pp. 541-564, 2002.

[12] Singh, Narinder, and S. B. Singh. "Hybrid algorithm of particle swarm optimization and Grey Wolf optimizer for improving convergence performance." Journal of Applied Mathematics2017 (2017).

[13] M. Farhoodnea, A. Mohamaed and H. Shareef, "A New Method for Determining Multiple Harmonic Source Location in a Power Distribution System," IEEE International Conference on Power and Energy (PECon), pp. 146-150, 29 December 2010 